\title{
APP Anterograde Transport Requires Rab3A GTPase Activity for Assembly of the Transport Vesicle
}

\author{
Anita Szodorai, ${ }^{2}$ Yung-Hui Kuan, ${ }^{2,9}$ Silke Hunzelmann, ${ }^{1,2}$ Ulrike Engel, ${ }^{4}$ Ayuko Sakane, ${ }^{6}$ Takuya Sasaki, ${ }^{6}$ Yoshimi Takai, ${ }^{7}$ \\ Joachim Kirsch, ${ }^{3}$ Ulrike Müller, ${ }^{5}$ Konrad Beyreuther, ${ }^{2,10}$ Scott Brady, ${ }^{8}$ Gerardo Morfini, ${ }^{8}$ and Stefan Kins ${ }^{1,2}$ \\ ${ }^{1}$ Technical University of Kaiserslautern, Department of Human Biology and Human Genetics, D-67663 Kaiserslautern, Germany, ${ }^{2}$ Centre for Molecular \\ Biology, ${ }^{3}$ Department of Anatomy and Cell Biology, ${ }^{4}$ Nikon Imaging Center, Bioquant, and ${ }^{5}$ Institute for Pharmacia and Molecular Biotechnology, \\ University of Heidelberg, D-69120 Heidelberg, Germany, ${ }^{6}$ Department of Biochemistry, Institute of Health Biosciences, The University of Tokushima \\ Graduate School, Tokushima 770-8503, Japan, ${ }^{7}$ Division of Molecular and Cellular Biology and Department of Biochemistry and Molecular Biology, Kobe University \\ Graduate School of Medicine/Faculty of Medicine, Kobe 650-0017, Japan, ${ }^{8}$ Department of Anatomy and Cell Biology, University of Illinois at Chicago, Chicago, \\ Illinois 60612, ${ }^{9} \mathrm{Max}$ Planck Institute for Brain Research, D-60528 Frankfurt, Germany, and ${ }^{10}$ Network Aging Research, D-69115 Heidelberg, Germany
}

The amyloid precursor protein (APP) is anterogradely transported by conventional kinesin in a distinct transport vesicle, but both the biochemical composition of such a vesicle and the specific kinesin-1 motor responsible for transport are poorly defined. APP may be sequentially cleaved by $\beta$ - and $\gamma$-secretases leading to accumulation of $\beta$-amyloid $(\mathrm{A} \beta)$ peptides in brains of Alzheimer's disease patients, whereas cleavage of APP by $\alpha$-secretases prevents $\mathrm{A} \beta$ generation. Here, we demonstrate by time-lapse analysis and immunoisolations that APP is a cargo of a vesicle containing the kinesin heavy chain isoform kinesin-1C, the small GTPase Rab3A, and a specific subset of presynaptic protein components. Moreover, we report that assembly of kinesin-1C and APP in this vesicle type requires Rab3A GTPase activity. Finally, we show cleavage of APP in transport vesicles by $\alpha$-secretase activity, likely mediated by ADAM10. Together, these data indicate that maturation of APP transport vesicles, including recruitment of conventional kinesin, requires Rab3 GTPase activity.

\section{Introduction}

The amyloid precursor protein (APP) is a type I transmembrane protein undergoing processing through sequential cleavage by either $\alpha$-secretase, including ADAM10 or ADAM17 (ADAM: a disintegrin and metalloproteinase), or $\beta$-secretase BACE1 ( $\beta$-site APP cleaving enzyme 1) and a proteolytic complex termed $\gamma$-secretase (Selkoe, 2001; Reinhard et al., 2005). $\beta$-Amyloid (A $\beta$ ) peptides, which accumulate in brains of Alzheimer's disease patients, are produced by the sequential activities of BACE1 and $\gamma$-secretase. Initial studies speculated that APP is rapidly transported in a membranous axonal organelle that also contains BACE1 and $\gamma$-secretase and that these proteases promoted APP proteolysis within transport vesicles during transit along the axon (Kamal et al., 2001). In contrast, others reported that Presenilin1 (PS1) and BACE1 have transport kinetics distinct from those of APP (Lazarov et al., 2005; Goldsbury et al., 2006).

Anterograde transport of APP is clearly mediated by conventional kinesin (kinesin, kinesin-1) (Koo et al., 1990; Ferreira et al.,

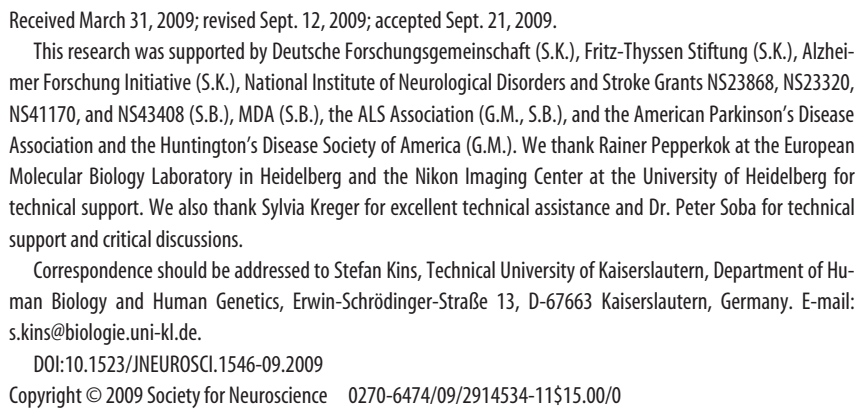
mer Forschung Initiative (S.K.), National Institute of Neurological Disorders and Stroke Grants NS23868, NS23320, NS41170, and NS43408 (S.B.), MDA (S.B.), the ALS Association (G.M., S.B.), and the American Parkinson's Disease Association and the Huntington's Disease Society of America (G.M.). We thank Rainer Pepperkok at the European Molecular Biology Laboratory in Heidelberg and the Nikon Imaging Center at the University of Heidelberg for technical support. We also thank Sylvia Kreger for excellent technical assistance and Dr. Peter Soba for technical support and critical discussions.

Correspondence should be addressed to Stefan Kins, Technical University of Kaiserslautern, Department of Human Biology and Human Genetics, Erwin-Schrödinger-Straße 13, D-67663 Kaiserslautern, Germany. E-mail: s.kins@biologie.uni-kl.de.

D0I:10.1523/JNEUROSCl.1546-09.2009

Copyright $\odot 2009$ Society for Neuroscience $\quad 0270-6474 / 09 / 2914534-11 \$ 15.00 / 0$

1992; Amaratunga et al., 1993; Simons et al., 1995; Tienari et al., 1996) with velocities of up to $10 \mu \mathrm{m} / \mathrm{s}$ (Kaether et al., 2000; Stamer et al., 2002; Goldsbury et al., 2006) in a vesicle type morphologically distinct from that of synaptophysin-containing vesicles (Kaether et al., 2000). However, the precise mode of connecting conventional kinesin with APP-containing transport vesicles remains controversial, and various models have been proposed. Based on immunoprecipitation experiments (Kamal et al., 2000) and fast axonal transport (FAT) studies in squid axoplasm (Satpute-Krishnan et al., 2006), a direct interaction of the APP C terminus with kinesin light chains (KLCs) was proposed. Inomata et al. (2003) later reported that the interaction between APP and KLCs might be mediated by c-Jun N-terminal kinase-interacting protein $1 \mathrm{~b}$ (JIP1b). However, more recent data showed that knockdown of JIP1b did not affect localization of APP at the distal end of neurites (Kins et al., 2006) and that KLCs do not interact directly with the cytoplasmic tail of APP (Lazarov et al., 2005), arguing against an essential role of the APP $\mathrm{C}$ terminus and JIP1b in the anterograde transport of APP. Moreover, heterologously expressed APP lacking the C-terminal intracellular domain continued to be transported anterogradely along the axon, indicating that the $\mathrm{C}$ terminus of APP was not required for anterograde FAT (Tienari et al., 1996; Torroja et al., 1999; Back et al., 2007; Rusu et al., 2007). Together, these data argue that APP does not interact directly with conventional kinesin but do not indicate how conventional kinesin mediates anterograde APP transport. Using biochemical and live cell imaging approaches, we show unequivocally that the APP C terminus is not essential for anterograde FAT of APP. Moreover, our data indicate that Rab3A GTPase activity is required for assembly of 
kinesin-1C, APP, and ADAM10 in a FAT vesicle of unique biochemical composition.

\section{Materials and Methods}

cDNA cloning and plasmids. Green fluorescent protein (GFP), human APP695 cDNA, or APP695 lacking its C terminus (APP $\Delta C T$; amino acids 1-649) fused to GFP, red fluorescent protein (RFP) or a hemagglutinin (HA) tag were cloned by PCR-based mutagenesis into pCDNA3.1 (Invitrogen). Phosphorylated enhanced green fluorescent protein-synaptophysin and phosphorylated enhanced cyan fluorescent protein (CFP)-synaptophysin were kind gifts from C. Kaether (Leibniz Institute for Age Research, Jena, Germany) and T. Dresbach (Institute for Anatomy and Cell Biology, Heidelberg, Germany). pcDNA-Rab3A/B/C/D wild-type and mutant Q81L constructs were a kind gift from M. Zerial (Max Planck Institute of Molecular Cell Biology and Genetics, Dresden, Germany). Phosphorylated cytomegalovirus (pCMV)-myc-Rab3GAP p130 and pCMV-myc-Rab3GAP p150 were constructed as described previously (Nagano et al., 1998). For generation of short hairpin RNA (shRNA) constructs, synthetic sense and antisense shRNA-oligos were annealed and then cloned into pKD (Dharmacon) by Sma1/EcoR1. The following oligos were used: human Rab3GAP p130, sh-sense oligo, GGAACTACTTCAACAGATATCAAGAGATATCTGTTGAAGTAGTTCCTTTTTGGGAACTACTTCAACAGATATCAAGAGATATCTGTTGAAGTAGTTCCTTTTTG; human Rab3GAP p130, sh-antisense oligo, AATTCAAAAAGGAACTACTTCAACAGATATCTCTTGATATCTGTTGAAGTAGTTCCAATTCAAAAAGGAACTACTTCAACAGATATCTCTTGATATCTGTTGAAGTAGTTCC; human Rab3GAP p150, sh-sense oligo, ATATGTCTGTCTCCATGTATCAAGAGATACATGGAGACAGACATATTTTTTGATATGTCTGTCTCCATGTATCAAGAGATACATGGAGACAGACATATTTTTTG; human Rab3GAP p150, sh-antisense oligo, AATTCAAAAAATATGTCTGTCTCCATGTATCTCTTGATACATGGAGACAGACATATAATTCAAAAAATATGTCTGTCTCCATGTATCTCTTGATACATGGAGACAGACATAT. Small interfering RNAs (siRNAs) targeting mouse Rab3GAP p130 were purchased from Invitrogen.

Antibodies. Primary antibodies directed against APP C terminus (CT20) (Calbiochem), APP N terminus (22C11) (Weidemann et al., 1989; Hilbich et al., 1993), ADAM10 (Calbiochem), ADAM17 (Calbiochem), BACE1 (Calbiochem), bassoon (Synaptic Systems), cortactin (Millipore Corporation), GAP43 (Sigma), GFP (Sigma, Santa Cruz Biotechnology), Grp78 (Stressgen), HA epitope (Roche), KDEL (Stressgen), kinesin-1 (H2) (Pfister et al., 1989), kinesin-1A (PA1-642; Affinity Bioreagents), kinesin-1B (UIC81 serum) (DeBoer et al., 2008), Munc13-1 (Synaptic Systems), Munc18 (Synaptic Systems), myc epitope (Sigma), N-Cadherin (Santa Cruz Biotechnology), Nicastrin (Millipore Bioscience Research Reagents), Piccolo (Synaptic Systems), PS1 (Santa Cruz Biotechnology), Rab3 (Synaptic Systems), Rab3GAP p130 and Rab3GAP p150 (Sakane et al., 2006), RIM2 (Synaptic Systems), SNAP25 (Synaptic Systems), synapsin-I (BioTrend), synaptophysin (Sigma), syntaxin-1B (Sigma), and Trk (Sigma). Secondary anti-mouse or anti-rabbit antibodies used for immunocytochemical or Western blot analyses were conjugated to Alexa Fluor 488 or 594 (heavy and light chain) (Invitrogen) or HRP (Promega), respectively.

Live cell time-lapse microscopy and kymograph analysis. Fluorescence microscopy of living cells transiently expressing fluorescent fusion proteins (16-18 h after transfection) was performed on a Nikon TE2000-E equipped with a $60 \times$ Planapo VC numerical aperture (NA) 1.45 or a Carl Zeiss Axiovert 200M Inverted Microscope equipped with a $100 \times$ Carl Zeiss NA 1.45 microscope. Images were recorded with a Hamamatsu Orca AG camera using NIS-Elemens software 3.2 (Nikon) or MetaMorph Imaging System (Universal Imaging Corporation). Dual-channel time-lapse (CFP/GFP, RFP) was performed with fast excitation and emission filter wheels (Lambda 10-2; Sutter Instruments). Cells were kept at $37^{\circ} \mathrm{C}$ with a stage top-heating chamber (Tokai Hit). For kymograph analyses, images were captured every $200 \mathrm{~ms}$ for a maximum of 2 min. Manual and automatic tracking, velocity analyses, and kymographs were generated by the use of the multiple kymograph function of the NIH ImageJ software or MetaMorph Imaging System (Universal Imaging Corporation). The slope of the traces is a direct measure for the velocity of the vesicles [ $v=\operatorname{cotan}(\alpha)$, where $\alpha$ is the angle relative to the $x$-axis]. Single tracks with an angle $0<\alpha<90^{\circ}$ were defined as anterograde, and tracks with a slope $90^{\circ}<\alpha<180^{\circ}$ were defined as retrograde transport vesicles. Tracks with slopes of $90^{\circ}$ (parallel to the time axis) were determined as stationary vesicles. The SEM was calculated, and a two-tailed $t$ test was used for statistical significance determination.

Cell culture. SH-SY5Y cells (American Type Culture Collection number CRL-2266) were cultivated in 50\% MEM, 50\% nutrient mixture F-12, Ham's medium, 1\% MEM nonessential amino acids, 1\% L-glutamine, 1\% penicillin/streptomycin, and $15 \%$ fetal calf serum (FCS). Mouse primary neurons were isolated and cultured as described previously (Kuan et al., 2006). Mouse neuroblastoma N2a cells were cultivated in MEM, $1 \%$ MEM nonessential amino acids, $1 \%$ L-glutamine, $1 \%$ penicillin/streptomycin, $1 \%$ sodium pyruvate, and 10\% FCS. For time-lapse microscopy and immunocytochemical analysis, SH-SY5Y cells and primary neurons were grown on poly-L-lysine (Sigma)-treated coverslips (Marienfeld). SH-SY5Y cells and mixed cortical primary neurons [day in vitro 1 (DIV1) or DIV7] from mouse embryos (embryonic day 14) were transfected using Lipofectamine Plus (Invitrogen) or Lipofectamine 2000 (Invitrogen), respectively, as described by the manufacturer.

Subcellular fractionation of brain membrane vesicles. Wild-type mice $(129 \mathrm{~Sv} \times$ C57BL6 Fx; 129OLA $\times$ C57BL/6 Fx; C57BL/6 $)$ and APP knock-out mice (129OLA $\times$ C57BL/6 Fx) (Li et al., 1996b) were used for the isolation of membrane and vesicle preparations, as described previously (DeBoer et al., 2008). Mouse brains were homogenized in $\sim 4$ vol of ice-cold HOM buffer (300 mm sucrose, $10 \mathrm{~mm}$ HEPES, pH 7,4, 5 mм EDTA, and 1:25 protease inhibitor cocktail) with a glass Teflon homogenizer and centrifuged for $5 \mathrm{~min}$ at $1200 \times \mathrm{g}, 5000 \times \mathrm{g}$, and $10,000 \times \mathrm{g}$ (for brain homogenate) and at $100,000 \times g$ for $30 \mathrm{~min}$ (Sorvall S45A rotor). The membranes were underloaded on a linear gradient $(5-23 \%$ iodixanol in HOM buffer) (OptiPrep) and centrifuged at 150,000 $\times g$ for $90 \mathrm{~min}$. Fifteen equal fractions were either collected and analyzed or pooled light density vesicle fractions (fractions $1-5$ ) were used as starting material for immunoisolation experiments.

Immunoisolation and immunoprecipitation. Antibodies directed against APP (CT20) and kinesin-1 (H2) were crosslinked to anti-mouse or anti-rabbit IgG M-280 magnetic beads (Dynal/Invitrogen) using dimethyl pimelinediimidate dihydrochloride (DMP) (Fluka) or dithiobis succinimidyl propionate (Pierce) according to the instructions of the manufacturer.

Whole-brain homogenates or iodixanol gradient-purified membrane fractions were incubated with CT20-coupled magnetic beads for $4-12 \mathrm{~h}$ at $4^{\circ} \mathrm{C}$. After extensive washing, the immunoisolates were treated with either 1\% (v/v) Nonidet P-40 (NP-40) (Fluka) or chlamidopropyl dimethylammonio-1-propane-sulfonate (CHAPS) (Sigma) in PBS at $4^{\circ} \mathrm{C}$ for $30 \mathrm{~min}$ or directly heated $\left(5 \mathrm{~min}, 95^{\circ} \mathrm{C}\right)$ in loading buffer. The supernatants of detergent-treated samples were discarded. The beads were denatured in loading buffer (Kuan et al., 2006) and subjected to Western blot analyses.

For sequential immunoisolations, brain membrane fractions were incubated with CT20-coupled magnetic beads as described above. After washing, the beads were treated with PBS containing $250 \mathrm{~mm}$ DTT overnight at $4^{\circ} \mathrm{C}$. Eluted membranes were diluted (sixfold) in PBS and then incubated with $\mathrm{H} 2$-coupled magnetic beads for $4 \mathrm{~h}$ at $4^{\circ} \mathrm{C}$. Finally, APP/ kinesin-1 double immunoisolated membranes were processed for Western blot analyses.

For $\alpha$-secretase inhibition experiments, a membrane permeable zincspecific chelator [ $N, N, N^{\prime}, N^{\prime}$-tetrakis-(2-pyridylmethyl)-ethylenediamine (TPEN)] (Sigma) was added at a concentration of $10 \mu \mathrm{M}$ directly after mouse brain homogenization for the entire purification procedure (Fonte et al., 2001).

Immunocytochemistry. SH-SY5Y cells and mixed cortical primary neurons were grown on poly-L-lysine (Sigma)-coated coverslips (Marienfeld) in 24-well plates (Falcon) and fixed with 4\% paraformaldehyde (Sigma) for 30 min, permeabilized for $10 \mathrm{~min}$ in PBS with $0.1 \%$ NP-40, and blocked in PBS with 5\% (v/v) goat serum (Sigma) for $1 \mathrm{~h}$. After incubation with primary and secondary antibodies, the coverslips were embedded in Mowiol (Sigma) and analyzed by fluorescence microscopy $(60 \times$ objec- 
tive, FITC or cyanine 5 filters) as described in detail previously (Kuan et al., 2006).

\section{Results}

Anterograde fast axonal transport of APP is independent of its intracellular domain

Immunocytochemical and immunohistological analyses of APP lacking the C terminus $(\mathrm{APP} \Delta \mathrm{C})$ in primary neurons and Drosophila motor neurons revealed that APP undergoes anterograde FAT in the absence of its C terminus (Tienari et al., 1996; Torroja et al., 1999; Back et al., 2007; Rusu et al., 2007). However, these experiments did not examine whether APP anterograde FAT rates might be altered by deletion of the APP C-terminus, nor did they evaluate whether APP and APP $\Delta$ CT are cotransported in the same type of vesicles. To address these issues, we performed live microscopy studies of GFP fusion proteins with APP (APP-GFP) and APP lacking the $\mathrm{C}$ terminus (APP $\Delta \mathrm{CT}$ GFP) in primary neurons. Mixed cortical neurons (DIV7) were transfected with cDNAs encoding either APP-GFP or APP $\triangle$ CT-GFP and analyzed by timelapse microscopy $18 \mathrm{~h}$ after transfection (Fig. $1 A-C$ ). Velocity analysis revealed that APP-GFP is transported with a maximal velocity of $\sim 7-10 \mu \mathrm{m} / \mathrm{s}$ (Fig. 1) (supplemental Fig. 1, available at www. jneurosci.org as supplemental material), consistent with previous studies (Kaether et al., 2000; Goldsbury et al., 2006). Detailed analyses of APP-GFP and APP $\Delta$ CT-GFP transport rates (Fig. 1D) revealed that APP $\triangle \mathrm{CT}-\mathrm{GFP}$ movement was indistinguishable from full-length APP-GFP, arguing that the APP C terminus is not required for packaging of APP in the anterograde transport vesicles or docking of conventional kinesin. To determine whether APP and APP $\Delta$ CT are transported in the same type of vesicles, we cotransfected primary neurons with APP-RFP and APP $\Delta$ CT-GFP. The two fluorescent proteins were visualized sequentially with a time interval of 200 $\mathrm{ms}$ (exposure time and time for changing the filter). We observed that anterograde movements of both fusion proteins were highly correlated. After tracking anterogradely transported vesicles, velocity kinetics were determined. This analysis revealed identical trafficking characteristics for APP-RFP and APP $\triangle$ CT-GFP (supplemental Fig. $1 B$, available at www.jneurosci.org as supplemental material), indicating that they were cotransported in the same type of vesicle. Consistent with previous studies (Kaether et al., 2000), we found that synaptophysin-CFP was transported in a different type of transport vesicle from APP-RFP and APP $\Delta$ CTGFP (data not shown), indicating that heterologously expressed APP fusion proteins are targeted to a specific type of transport vesicles. Recently, we reported that APP forms homotypic cisdimers (Soba et al., 2005). To exclude the possibility that APP $\triangle$ CT-GFP might be cotransported by associating to endogenous APP, we used primary neurons from APP knock-out mice transfected with APP $\triangle$ CT-GFP for time-lapse analysis. These
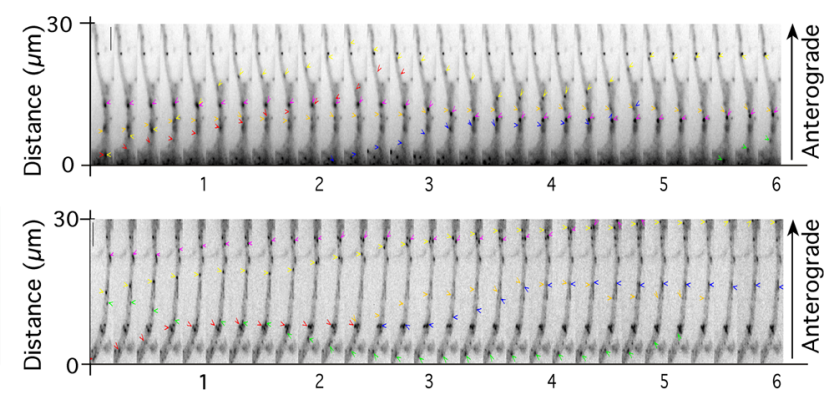

$0+$
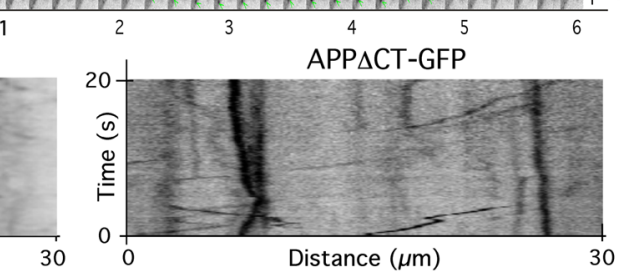

Distance $(\mu \mathrm{m})$

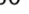

Distance $(\mu \mathrm{m})$

30

APP-GFP

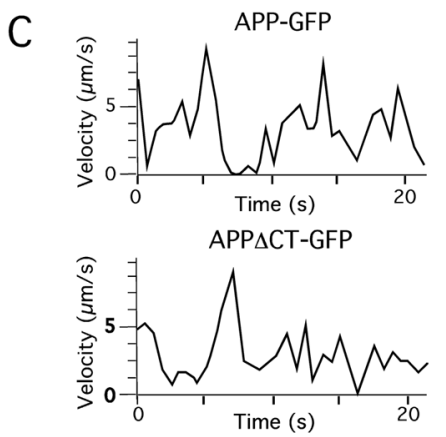

D

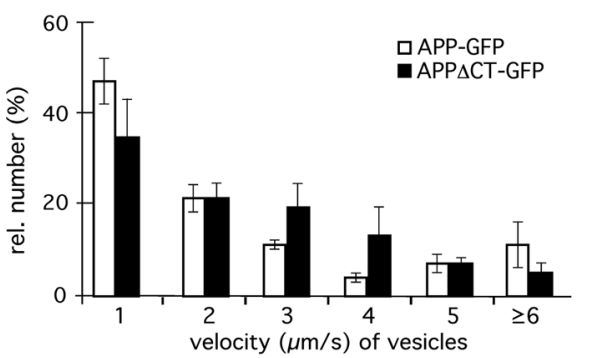

Figure 1. APP can be transported by the fast axonal transport machinery in the absence of its intracellular C terminus. Mouse primary cortical neurons (DIV7) expressing APP_GFP and/or APP $\triangle$ CT-GFP were analyzed by time-lapse microscopy $18 \mathrm{~h}$ after

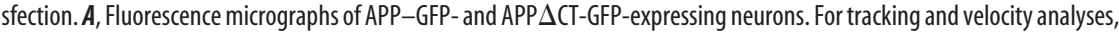
indicate the single vesicles that have been examined. Time interval between images was $200 \mathrm{~ms}, 5$ images/s. $\boldsymbol{B}$, Representative

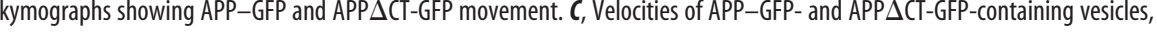
assayed over a period of $22 \mathrm{~s}$. D. Histogram showing quantification of the number of recorded vesicles moving at velocities of 1,2 , $3,4,5$, or $>6 \mu \mathrm{m} / \mathrm{s}$. No statistical significant differences between the velocities of APP-GFP-and APP $\Delta$ CT-containing transport vesicles could be determined (Student's t test, $p \geq 0.2$ ). Scale bar, $25 \mu \mathrm{m}$.

studies showed that the FAT machinery transports APP $\triangle \mathrm{CT}-$ GFP even in the absence of endogenous APP (supplemental Fig. $1 A$, available at www.jneurosci.org as supplemental material). Consistently, analysis of APP-GFP and APP $\triangle$ CT-GFP transport in APP/APLP1/APLP2 triple-knock-out mouse embryonic fibroblasts revealed no differences of their fast transport characteristics $(1-4 \mu \mathrm{m} / \mathrm{s}$ ) (data not shown). Together, these data suggest that the APP C terminus is not required for FAT of APP.

APP is a cargo of a kinesin-1C associated transport vesicle Previous studies indicated that APP-containing vesicles are transported by conventional kinesin. The holoenzyme of conventional kinesin exists as a tetramer consisting of two KLCs and two kinesin heavy chain (kinesin-1, KHC, KIF5s) subunits (DeBoer et al., 2008). Following the standard nomenclature for kinesins, the term "conventional kinesin" herein refers to the tetrameric motor protein complex (heavy and light chains), whereas "kinesin-1" refers exclusively to the heavy chain subunits (Lawrence et al., 2004; DeBoer et al., 2008). To identify specific kinesin-1 isoform(s) linked to APP-containing vesicles and characterize the APP cargo vesicle, we performed immunoisolations from crude mouse brain membrane fractions, using magnetic beads loaded with an antibody directed against the $\mathrm{C}$ terminus of APP (CT20-coupled beads). APP immunoisolates were analyzed by 


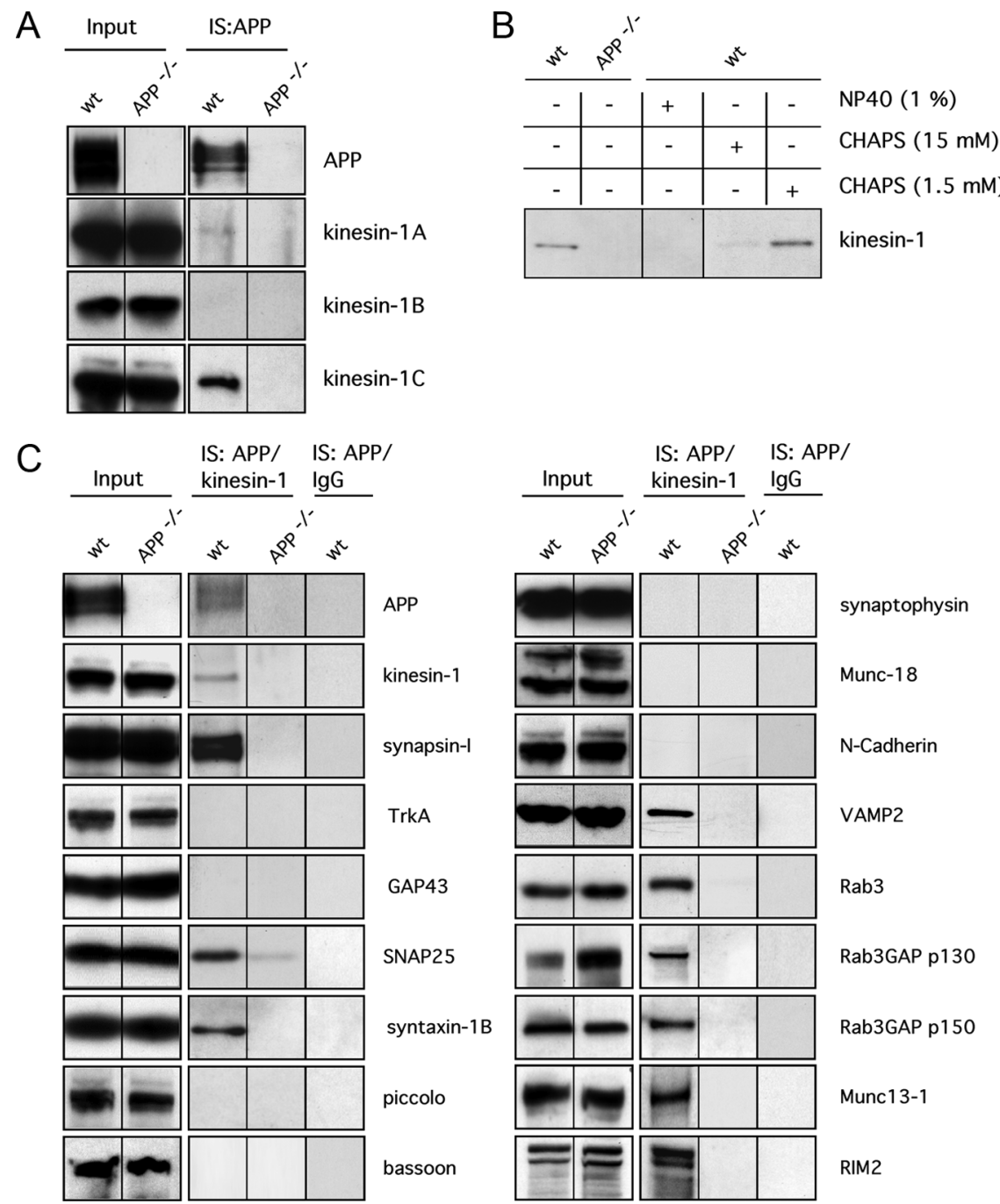

Figure 2. APP is a cargo of an axonal transport vesicle containing presynaptic components and is associated with kinesin-1C. $A$, Immunoisolations (IS) of APP using an anti-APP antibody (CT20) from wild-type (wt) and APP knock-out (APP ${ }^{-1-}$ ) mouse brain homogenates. Each lysate ( $1 / 80$ ) was loaded as input control (Input). Western blot analyses of APP immunoisolates with antibodies against specific kinesin- 1 s revealed that APP is mainly associated with kinesin- $1 C$. $B$, Immunoisolated APP containing membrane preparations from wild-type mice (wt) were treated with 1\% (v/v) NP-40 (lane 3), $15 \mathrm{~mm} \mathrm{CHAPS} \mathrm{(lane} \mathrm{4),} 1.5 \mathrm{~mm}$ CHAPS (below the critical micellar concentration) (lane 5), or no detergent (lane 1). An immmunoisolate using anti-APP antibody obtained from APP knock-out mice (APP ${ }^{-1-}$ ) is shown as a control (lane 2). C, Total mouse brain membrane fractions were separated on a linear iodixanol gradient (supplemental Fig. 2, available at www.jneurosci.org as supplemental material), and low-density membrane fractions (fractions 1-5) were pooled and used for a two-step immunoisolation: vesicles were first immunoisolated with an anti-APP antibody (IS:APP). After these, immunoisolated membranes were eluted and subject to immunoisolation with an antikinesin-1 antibody (H2) (IS: APP/kinesin-1) (for details, see Materials and Methods). Coimmunoisolated proteins were separated by SDS-PAGE and subjected to Western blot analysis. Brain homogenates from APP knock-out (APP ${ }^{-1-}$ ) mice were used for immunoisolation with anti-APP antibody as a control for nonspecific binding. To test for specificity of anti-kinesin-1 immunoisolations, a non-immune lgG fraction (lgG) was used (IS:APP/lgG).

immunoblotting using antibodies that specifically recognize different kinesin-1 gene products: kinesin-1A, kinesin-1B, and kinesin-1C [formerly KIF5A, KIF5B, and KIF5C, respectively (Lawrence et al., 2004)] (DeBoer et al., 2008) (Fig. 2A). No immunoreactivity was detected with an antibody against kinesin-1B (specific antibodies used are described in Materials and Methods), and barely detectable amounts of kinesin-1A were present in the APP immunoisolates. The anti-kinesin-1 antibody $(\mathrm{H} 2)$ reacting with both kinesin-1A and kinesin-1C (DeBoer et al., 2008) displayed significant immunoreactivity when reacted with APP immunoisolated fractions (Fig. $2 A)$. The $\mathrm{H} 2$ immunoreactive band in the APP immunoisolates migrated at a significant lower molecular weight than kinesin-1A and could therefore be clearly identified as kinesin-1C (DeBoer et al., 2008). Thus, conventional kinesin associated with APP-containing membranes is mainly composed of kinesin-1C. Specificity of the kinesin-1C immunoreactivity in APP immunoisolates was verified using brain homogenates from APP knock-out mice (Fig. $2 A)$. In the absence of endogenous APP, we did not observe nonspecific binding of any kinesin-1 isoform to immunoisolates obtained with the CT20-loaded magnetic beads (Fig. $2 A$ ).

APP can be associated with a variety of membrane structures, including Golgi, endoplasmic reticulum (ER), and transport vesicles (Kins et al., 2006). To enrich for membrane fractions containing axonal transport vesicles, we separated the brain extracts in a linear iodixanol gradient $(5-23 \%)$. We thus obtained lowdensity membrane material enriched with presynaptic marker proteins such as GAP43, synapsin-IA/B, and synaptophysin (supplemental Fig. 2, available at www.jneurosci. org as supplemental material). These membranes were mostly separated from ER or cis-Golgi membrane fractions, as evidenced by low levels of typical ER and cis-Golgi markers (anti-Grp78 and anti-KDEL). Significantly, APP immunoisolates obtained from pooled membrane fractions 1-5 from wild-type mouse brains also contained kinesin-1C (Fig. 2B). As before (Fig. 2A), immunoisolates prepared from APP knockout mouse brain contained no kinesin- 1 immunoreactivity and served as negative controls (Fig. 2B). Treatment of the APPimmunoisolated membranes with detergents (i.e., 1\% NP-40 or 15 mm CHAPS) caused a loss of kinesin-1C from APP immunoisolates (Fig. 2B). In contrast, treatment of immunoisolates with concentrations of CHAPS ( $1.5 \mathrm{~mm}$ ) below the critical micellar concentration (Kratohvil, 1984; Partearroyo et al., 1988) did not cause a dissociation of kinesin-1C from APP beads (Fig. 2B). Crosslinking of APP immunoisolates with DMP before treatment with detergent did not maintain the APP/kinesin interaction (data not shown). Combined with the live cell analyses of transport of APP lacking the $\mathrm{C}$ terminus, these data suggest that conventional kinesin containing kinesin-1C heavy chains associates with APP transport vesicles in a manner independent of the APP C terminus.

\section{Characterization of APP transport vesicles}

To characterize APP-containing membrane compartments moving in FAT (i.e., transport vesicles) in more detail, we performed two sequential immunoisolations with CT20 and H2-loaded magnetic beads. APP-containing membrane compartments were prepared as described previously using beads linked with a disul- 

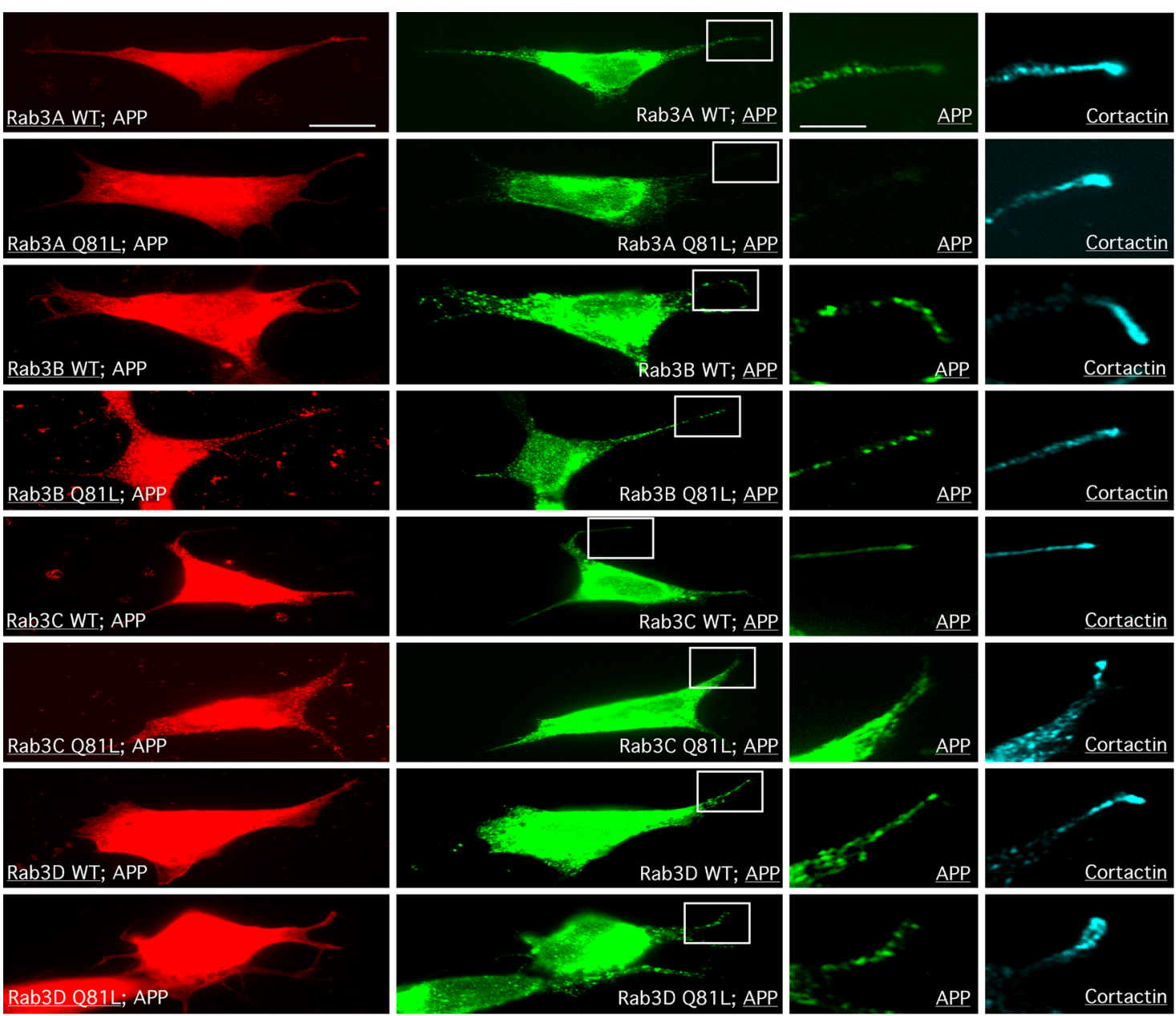

Figure 3. Rab3-subtype-specific influence on APP localization. To determine specific Rab3 family members that might be essential for anterograde transport of APP, we tested the influence of both wild-type (wt) and GTPase-deficient mutant (Q81L) versions of GFP-tagged Rab3A-Rab3D on APP-HA localization at the distal end of growing neurites. Neuroblastoma cells (SH-SY5Y) were cotransfected with the different Rab3 constructs together with APP-HA CDNA and analyzed by immunocytochemistry using anti-GFP (red), anti-HA (green), and as a growth cone marker anti-cortactin (cyan) antibodies. Notably, only transfection with the Rab3A Q81 construct caused a reduction in the level of APP that normally accumulates at the distal ends of neurites. To visualize the neurites more clearly, the regions of interest (boxed) are shown at higher magnification in the two right columns. Scale bar, $10 \mu \mathrm{m}$. Higher-magnification bar, $3.3 \mu \mathrm{m}$.

fide crosslinker to CT20 antibodies. CT20 immunoisolates were then treated with DTT to elute APP-containing membranes and subjected to a second round of immunoisolation using $\mathrm{H} 2$ loaded magnetic beads, allowing for the enrichment of membranes containing both APP and kinesin-1C.

Double APP/kinesin-1-immunoisolated membrane preparations were subjected to Western blot analysis, using various antibodies directed against a wide range of presynaptic and postsynaptic protein components. Only a subset of presynaptic proteins was detected in these APP/kinesin-1C double immunoisolates, including SNARE complex components (such as VAMP2, SNAP25, and syntaxin-1b) and synapsin-I, as well as components of the active zone, such as Rab3, RIM2, Munc13-1, and Rab3GAP p130 and p150 (Fig. 2C). Other presynaptic components previously described as putative cargoes of APP transport vesicles, including GAP43 and TrkA (Kamal et al., 2001), were not found in our membrane immunoisolates. Synaptophysin, a presynaptic protein previously shown to be transported in a different class of membranous organelles than APP (Kaether et al., 2000), was also absent. Neither postsynaptic proteins, such as the NMDA or AMPA receptor (data not shown), nor presynaptic cytomatrix proteins (Dresbach et al., 2001), such as bassoon and piccolo were detected in APP/kinesin-1C double immunoisolates (Fig. 2C). To control for specificity of the double immunoisolates, we used membrane preparations from APP knock-out mouse brain in the first APP immunoisolation step. Specificity of the kinesin-1 immunoisolation was verified by using nonimmune mouse Ig (Fig. 2C).

Immunoisolation experiments here show that APP/kinesin-1 coimmunoisolated membrane fractions contain a subset of presynaptic protein contents that included syntaxin, synapsin-I, Rab3, and several Rab3A associated proteins but did not include synaptophysin or typical protein components of the active zone, such as bassoon or piccolo. Together, these data strongly suggest that APP and other presynaptic membrane protein represent cargoes present in a biochemically distinct presynaptic membranous organelle, which in turn associates primarily with kinesin-1C.

\section{APP localization at growth cones depends on Rab3A GTPase activity}

Interestingly, some of the components identified in APP transport vesicles (i.e., Rab3GAP p130, Rab3GAP p150) are known to interact with and to stimulate the GTPase activity of Rab3 family members (Rab3A-Rab3D) (Fukui et al., 1997; Sakane et al., 

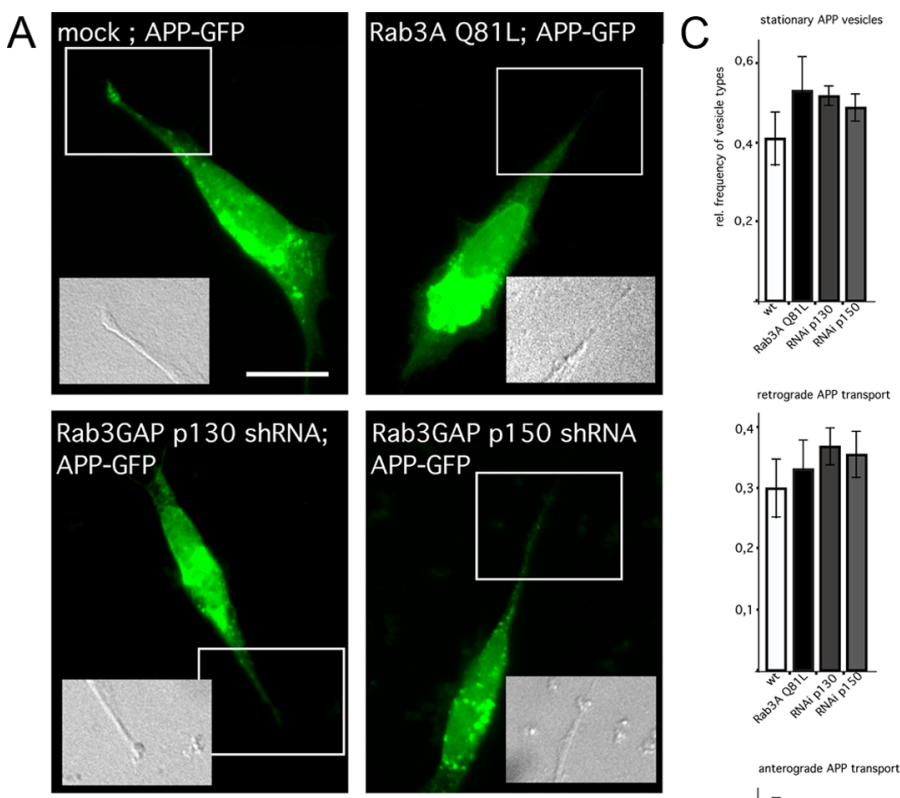

B
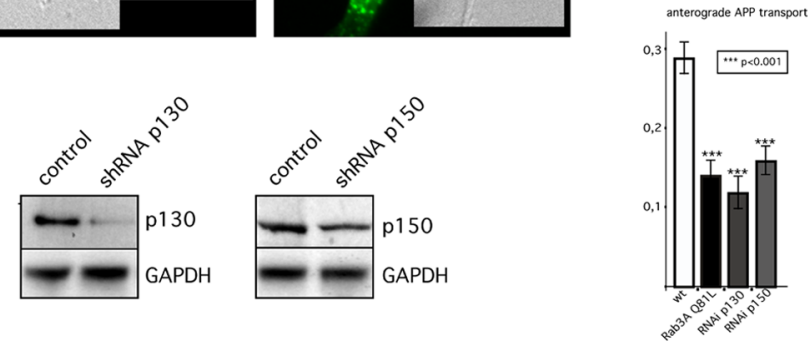

Figure 4. Rab3 GTPase activity is essential for APP fast anterograde transport. Neuroblastoma cells (SH-SY5Y) were cotransfected with APP-GFP cDNA and empty vector (mock), Rab3A Q81L CDNA, shRNA constructs directed against Rab3GAP p130, or Rab3GAP p150. A, Mock-transfected cells expressing APP-GFP displayed an accumulation of APP-GFP at the tips of neurites (box), whereas inhibition of Rab3A GTPase activity by expression of mutant Rab3A Q81L or silencing of Rab3GAP p130 or p150 caused a decrease of APP-GFP levels at the tips. Differential interference contrast images of the regions of interest/of the indicated regions (boxed) are shown as insets. Scale bar, $10 \mu \mathrm{m}$. $\boldsymbol{B}$, The silencing efficiency of the human Rab3GAP p130 or Rab3GAP p150 shRNA was of $\sim 40-60 \%$. Taking into account that the transfection rate with the vector-based shRNA constructs was 50-60\%, the knockdown efficiency per transfected cell was estimated to be $\sim 70$ - 80\%. GAPDH, Glyceraldehyde-3-phosphate dehydrogenase. C, APP-GFP (left) or synaptophysin-GFP (right) fusion proteins were analyzed by time-lapse microscopy ( 5 frames $/ \mathrm{s}$ ) in mock-transfected neuroblastoma cells (white columns), cells coexpressing Rab3A Q81L (black columns), or cells with knockdown [RNA interference (RNAi)] of Rab3GAP p130 (dark gray columns) or Rab3GAP p150 (light gray columns). Kymographs from single cells ( $n=12$ ) were analyzed. The relative frequencies of stationary, retrogradely, or anterogradely transported APP-GFP (left) or synaptophysin-GFP (right) containing vesicles was determined. The range of velocities for synaptophysin-GFP (syn) is lower (1-5 $\mu \mathrm{m} / \mathrm{s})$ than the range seen with APP (1-10 $\mu \mathrm{m} / \mathrm{s})$. Therefore, we determined only the relative frequency of anterograde APP-GFP vesicles moving at velocities $\geq 4 \mu \mathrm{m}$. Error bars represent SEM. ${ }^{* * *} p<0.001, t$ test.

2006). APP typically accumulates at the distal end of neurites (Ferreira et al., 1993; Morfini et al., 1997; Sabo et al., 2003), and inhibition of anterograde APP transport affects this accumulation (Ferreira et al., 1992; Morfini et al., 1997). We cotransfected neuroblastoma SH-SY5Y cells with APP-HA and specific Rab3 isoforms (Rab3A-Rab3D) and then examined accumulation of APP-HA at the growth cones of neurites (identified by costaining with the growth cone marker cortactin). Rab3 constructs used in these experiments included wild-type forms or GTPase-deficient mutants carrying a Q81L amino acid replacement (Johannes et al., 1994) (kind gifts from M. Zerial) (Fig. 3B). Significantly, only coexpression of the Rab3A GTPase-deficient mutant caused a reduction of APP levels at the neurite ends, suggestive of a deficit in the anterograde transport of APP. None of the other wild-type or mutant Rab3 isoforms altered APP distributions in SH-SY5Y cells (Fig. 3). These findings suggested that Rab3A GTPase activity is required for anterograde FAT of APP.
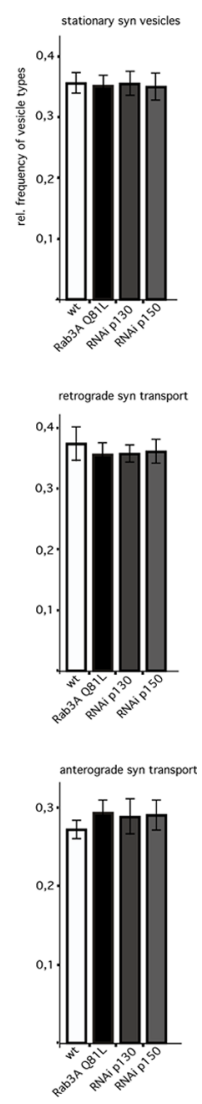

\section{Rab3A GTPase activity is essential for} fast anterograde transport of APP As an independent test of the hypothesis that Rab3A GTPase activity is required for APP anterograde transport, we knocked down Rab3GAP p130 and Rab3GAP p150 in SH-SY5Y cells using shRNA constructs. Western blot analysis showed a $40-60 \%$ reduction in Rab3GAP p130 levels (Fig. 4B). Because the transfection efficiency with the vector-based shRNA constructs was $50-60 \%$, the knockdown efficiency per transfected cell was estimated to be $\sim 70-80 \%$. Rab3GAP knockdown cells expressing APP-GFP exhibited accumulation of APP in the cell soma, and APP-GFP failed to accumulate in neurite ends (Fig. $4 A$ ). In contrast, mock-transfected cells exhibited the typical APPGFP accumulations at neurite ends (Fig. 4A). Notably, overexpression of Rab3GAPs p130 and p150 together with APP led to a more pronounced accumulation of APP at the growing tips (supplemental Fig. 3, available at www.jneurosci.org as supplemental material). To characterize the role of Rab3A GTPase activity in anterograde transport of APP further, we transfected SH-SY5Y cells with either the Rab3A Q81L mutant construct or with shRNA constructs directed against Rab3GAP p130 and p150. Cells were analyzed by time-lapse microscopy (5 frames/s) $18 \mathrm{~h}$ after APP-GFP cDNA transfection. APPGFP-expressing cells cotransfected with empty vector (Fig. $4 C$, white column) or wild-type Rab3A coexpressing cells served as controls (data not shown). To evaluate changes in APP transport rates, we calculated the relative frequencies of stationary ( $\leq 0.2 \mu \mathrm{m} / \mathrm{s})$, retrogradely $(>0.2 \mu \mathrm{m} / \mathrm{s})$, and anterogradely $(>0.2 \mu \mathrm{m} / \mathrm{s})$ transported APP-GFP-containing vesicles in 12 or more individual cotransfected cells for each construct tested. In neurites of control vector-transfected cells, we found in distal regions $41 \pm 7 \%$ (mean \pm SEM) stationary, $30 \pm 5 \%$ $($ mean \pm SEM $)$ retrogradely, and $29 \pm 2 \%$ (man \pm SEM) anterogradely transported APP-GFP vesicles (Fig. $4 C$ ). The relative frequencies of anterograde transport vesicles were significantly reduced after inhibition of Rab3A GTPase activity with the Rab3A Q81L mutant (14\%) or silencing of Rab3GAP p130 (12\%) or Rab3GAP p150 (16\%) ( $t$ test, $p<0.001$ ) (Fig. $4 C$ ), but frequencies of retrogradely transported and stationary membrane compartments were not significantly altered (Fig. 4C). These data indicate that Rab3A GTPase activity modulated fast anterograde transport of APP. To make sure that inhibition of Rab3A GTPase does not cause a general block of anterograde FAT, we evaluated FAT of synaptophysin-containing vesicles, which is carried in a different cargo vesicle than APP (Kaether et al., 2000) (Fig. 4C). Neither mutant Rab3A Q81L nor silencing of Rab3GAP p130 or p150 affected the relative frequencies of synaptophysin-GFP vesicles found 
in anterograde or retrograde FAT, suggesting that inhibition of Rab3A GTPase specifically affects the anterograde FAT of APP-containing vesicles. Together, these findings suggest that Rab3A GTPase activity is required for anterograde FAT of APP.

We also investigated the effects of Rab3GAP p130 knockdown on APP localization using primary cultured neurons. We treated stage 1 primary neurons with Rab3GAP p130 siRNA and analyzed the localization of endogenous APP (Fig. 5B). Treatment with Rab3GAP p130 siRNA caused a statistical significant reduction of Rab3GAP p130 levels to $64 \pm 9 \%$. As observed in SH-SY5Y cells, a clear reduction of APP accumulation at the tips of neurites was seen in primary neurons treated with the Rab3GAP p130 siRNA construct compared with control transfected cells (Fig. 5B,C). For quantification, we measured the intensity of GFP-APP in the cell body and the tip of neurites of single cells treated with control or Rab3GAP p130 siRNA ( $n=27$ for each) (Fig. $5 C$ ). Consistent with data obtained from SH-SY5Y cells, the ratio of GFP-APP intensity at tips/cell bodies was reduced by $\sim 40 \%$ in Rab3GAP p130 siRNA-treated cells compared with control treated cells. Silencing of Rab3GAP p130 caused a reduction of APP intensity at the tips and an accumulation of APP in the cell bodies, suggesting that Rab3A GTPase activity is also required for anterograde FAT of APP in primary neurons.

\section{The activities of Rab3GAP p130 and p150 are required for the attachment of conventional kinesin to}

\section{APP-containing vesicles}

Given that Rab3 GTPase activity is required for the anterograde FAT of APP, we speculated that conversion of Rab3A from GTPto-GDP bound states might be crucial for the correct assembly of APP transport vesicles. To test this possibility, we used isolated membranes from Rab3GAP p130 knock-out mice, which display reduced levels of Rab3A activity (Sakane et al., 2006). Significantly, the amounts of kinesin-1, Rab3, and the Rab3 associated proteins RIM2 and Munc13-1 were dramatically decreased in APP immunoisolates derived from Rab3GAP p130 knock-out brains compared with immunoisolates derived from wild-type mouse brain (Fig. 6). Regarding the activity-dependent association of Rab3A with membranes, this appears consistent with the reduction in Rab3A activity reported in brains of $\mathrm{p} 130^{-1-}$ knock-out mice (Sakane et al., 2006). Together, these data indicate that Rab3A GTPase activity is required for the correct assembly of APP into anterograde transport vesicles, including the packaging of membrane proteins, such as Rab3A, and the association of the motor protein conventional kinesin.

APP and ADAM10 are cargoes of a common transport vesicle In this study, we identified several novel putative cargo proteins present in APP-containing transport vesicles. The question of

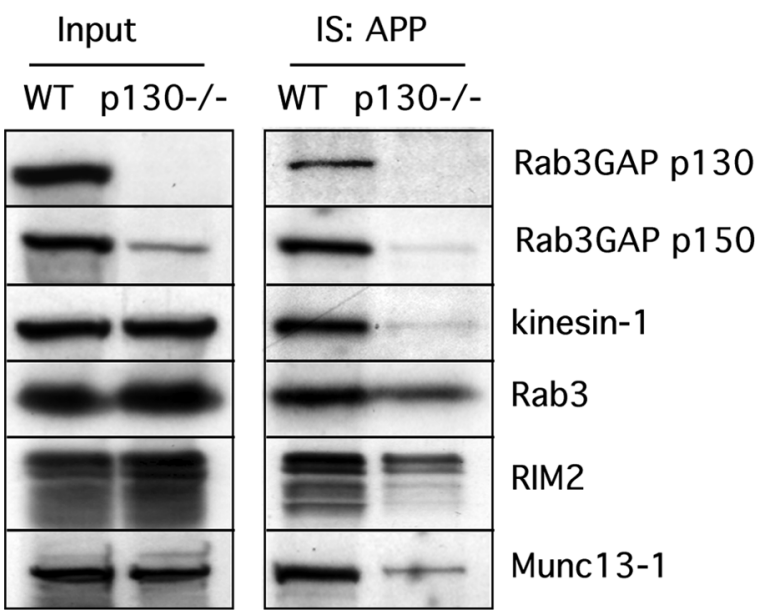

Figure 6. Loss of kinesin-1 from APP transport vesicles in Rab3GAP p130 knock-out mice. Low-density membrane fractions from wild-type (wt) or Rab3GAP p130 knock-out mouse $\left(\mathrm{p} 130^{-/-}\right.$) brain homogenates were immunoisolated with anti-APP antibodies (IS:APP) and subjected to Western blot analyses using antibodies directed against Rab3GAP p130, Rab3GAP p150, kinesin-1, Rab3, and two putative cargoes of APP transport vesicles, RIM2 and Munc13-1 (see Fig. 1). Total lysate (1/80) from each brain was loaded in the lanes of the left panel as input control (Input). 
A

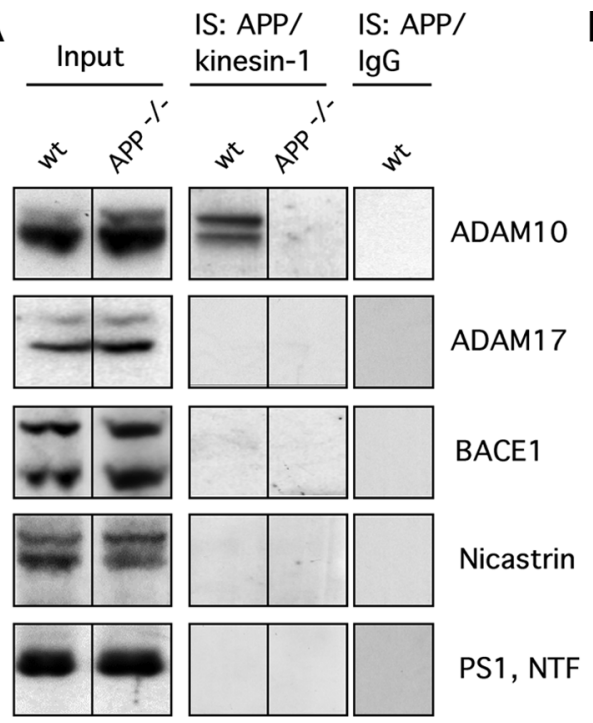

B

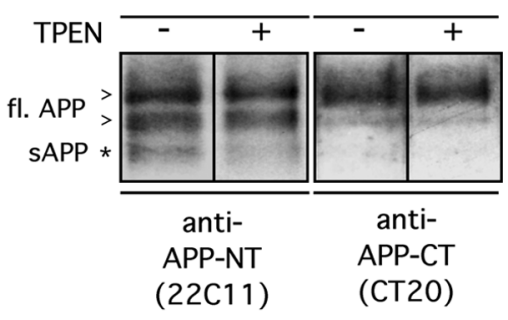

sAPP band was reduced in the presence of the $\alpha$-secretase inhibitor. Together, these data suggest that APP might be processed in the APP/kinesin-1 doubleimmunoisolated membrane compartment by $\alpha$-secretase activity, most likely mediated by ADAM10.

\section{Discussion}

The APP C terminus is not essential for fast anterograde transport

A role of APP as a cargo receptor for conventional kinesin has been a contentious issue (Kamal et al., 2000, 2001; Lazarov et al., 2005). Various reports proposed that transport of APP-containing vesicles depends on a direct interaction between the $\mathrm{C}$ terminus of APP and the KLCs of conventional kinesin, suggesting that APP acts as a motor protein adaptor/receptor (Kamal et al., 2000). Contrasting with predictions from this model, we and others showed that APP constructs lacking the C-terminal intracellular domain are transported to the nerve terminal (Tienari et al., 1996; Torroja et al., 1999; Back et al., 2007; Rusu et al., 2007). However, it was unclear whether the anterograde FAT of APP lacking its $\mathrm{C}$ terminus was mediated whether the APP-processing secretases BACE1 and PS1 are also cargo proteins in these vesicles has been controversial (Kamal et al., 2001; Lazarov et al., 2005; Goldsbury et al., 2006). To clarify this issue, we performed APP/kinesin-1 double immunoisolations as described above and examined the presence of APP secretases and APP processing in the isolated membrane fractions. In Western blot analysis of APP/kinesin-1 double immunoisolates from mouse brain homogenates, neither BACE1 nor PS1 were detectable (Fig. 7A). Nicastrin, another component of $\gamma$-secretase, was also undetectable in APP/kinesin-1 double immunoisolates (Fig. 7A). We also tested for the presence of the putative $\alpha$-secretases ADAM10 and ADAM17. From these, only ADAM10 was detected in double immunoisolates obtained from wild-type, but not from APP knock-out, mouse brain, suggesting that APP/kinesin-1 double-immunoisolated membrane compartments contain ADAM10 as a cargo protein.

Next, we evaluated APP processing in the isolated APP transport vesicle fraction. For this purpose, we probed APP/kinesin-1 double immunoisolates with an antibody directed against the APP N terminus [22C11, which recognizes both full-length APP and cleaved, secreted APP (sAPP)] and with an antibody directed against the APP $\mathrm{C}$ terminus (CT20, which recognizes full-length APP but not sAPP) (Fig. $7 B$ ). These analyses revealed a clear difference in the detected pattern of APP immunoreactivity. The 22C11 antibody recognized a lower-molecular-weight band, not detected by the C-terminal antibody, representing sAPP. To exclude nonspecific cross-reactivity of the 22C11 antibody, we tested the antibody on brain extracts of wild-type and APP knock-out mice. No immunoreactivity was seen with the 22C11 antibody in APP knock-out mice (data not shown). To test whether APP can be cleaved by $\alpha$-secretase in the APP/kinesin-1 double-immunoisolated membrane compartment, we treated the double-immunoisolated membrane fractions over a time period of $\sim 30 \mathrm{~h}$ with a membrane-permeable zinc chelator (10 $\mu \mathrm{M}$ TPEN) that inhibits $\alpha$-secretase activity (Fonte et al., 2001). The generation of the lower-molecular-weight putative

by mechanisms different from those underlying transport of fulllength APP. In this study, time-lapse analyses of fluorescently labeled APP demonstrates that APP lacking its C terminus is packed and transported in the same type of FAT vesicles as full-length APP. Treatment of APP/kinesin-1 coimmunoisolated membranes with detergents caused the dissociation of kinesin-1 from the APP-immunoisolated membranes, arguing against a direct interaction between these proteins. Together, our data demonstrate that APP is a cargo of a specific subset of membranes transported by conventional kinesin and not a receptor protein directly linking conventional kinesin via its $\mathrm{C}$ terminus to this vesicle type. However, additional analyses will be necessary to determine the molecular basis underlying the association of conventional kinesin with APP transport vesicles.

As with many integral membrane proteins, a fraction of the APP is returned by retrograde transport (Lazarov et al., 2007, their Fig. 1). Our analysis of APP-GFP transport included proximal dendrites. Because the microtubule cytoskeleton in this area is not uniformly organized (microtubules may exhibit both polarities), conventional kinesin-dependent transport can take place in both directions (retrogradely and anterogradely relative to the cell body). However, the presence of some APP in the endosomal compartments (Ferreira et al., 1993) is consistent with retrograde FAT.

\section{Kinesin-1C mediates axonal transport of APP}

Based on studies of APP transport after treatment with antisense oligos directed against kinesin-1B, it was assumed that APP anterograde transport is mediated by kinesin-1B (Ferreira et al., 1992; Kaether et al., 2000). However, in these studies, neither a specific reduction of kinesin-1B nor analyses of other kinesin-1 isoforms were performed. Here, we tested systematically for kinesin-1 family members (kinesin-1A, kinesin-B, kinesin-C) that might be selectively associated with APP-containing membrane 
fractions. Interestingly, we found that kinesin-1B was not detectable in APP immunoisolates, but kinesin-1C (and to a much lesser extent, kinesin-1A) is preferentially associated with APP transport vesicles. Recently, it was shown that conventional kinesin holoenzymes are formed of kinesin-1 homodimers, which associate with biochemically different cargoes (DeBoer et al., 2008). The selective association of APP-containing transport vesicles with kinesin-1C reported here appears consistent with a role of kinesin-1s in the targeting of conventional kinesin holoenzymes to specific membrane-bounded organelle cargoes (DeBoer et al., 2008).

\section{A presynaptic transport vesicle subtype contains both Rab3A and APP}

Our detailed biochemical characterization of APP transport vesicles in association with kinesin-1C revealed that these membrane compartments contained no postsynaptic protein contents but instead contained a subset of presynaptic proteins, including synapsin-I, SNAP25, syntaxin-1B, VAMP2, Munc13-1, RIM2, Rab3, and Rab3GAP p130 and p150. Significantly, all these protein cargoes are involved in various aspects of synaptic vesicle fusion. Thus, our results here are consistent with previous studies suggesting that APP may play a role in the regulation of vesicle fusion and synaptic function (Wang et al., 2005; Yang et al., 2007).

Rab3A was shown previously to be present in several different presynaptic vesicle types along with various other proteins, which are transported by different velocities along the ax including syntaxin-1, SNAP25, bassoon, piccolo, Munc18, N-Cadherin, and VAMP2 (Okada et al., 1995; Zhai et al., 2001), which are transported by different velocities along the axon (Shapira et al., 2003). Likely, APP transport vesicles represent only a subset of the cargo proteins that can be cotransported with Rab3A. Our data suggest that Rab3A may be involved in the packaging of specific proteins into different vesicle subtypes that in turn may be moved by specific motor proteins. In this regard, it is remarkable that inhibition of Rab3A had no influence on the anterograde transport of synaptophysin, although Rab3 colocalizes with synaptophysin at nerve terminals (Li et al., 1996a), and has been copurified from synaptic vesicles in immunoisolation experiments (Fischer von Mollard et al., 1990; de Wit et al., 1999). The anti-Rab3 antibody used in these two studies does not allow differentiating between the Rab3 isoforms. Thus, the apparent discrepancy between these studies and our analyses might be explained by the fact that synaptophysin is not a cargo of vesicles containing Rab3A but possibly a cargo of Rab3BRab3D-containing vesicles. Alternatively, Rab3A and synaptophysin may be packaged in a common vesicle after they have reached the nerve terminal in distinct transport vesicles, as suggested by previous immunoisolation studies (Okada et al., 1995). Consistent with this latter possibility, some components of the APP transport vesicle have been found in association with synaptic vesicle fractions (synapsin-I, syntaxin-1, SNAP25, etc.), although APP has not been found as a component of synaptic vesicles (Takamori et al., 2006).
Rab3A GTPase activity is required for APP transport By using a Rab3A GTPase-deficient mutant and by silencing of Rab3GAP p130 or p150, we showed that conversion of Rab3A-GTP to Rab3A-GDP is essential for anterograde FAT transport of APP in neuronal cells. These findings are consistent with previous experiments in isolated axoplasm indicating that FAT depends on the activity of small GTPases (Bloom et al., 1993). Rab3 GTPase family members are key regulators of presynaptic vesicular transport with overlapping, but not identical, functions (Burstein et al., 1993; Deneka et al., 2003; Schluter et al., 2004; Ali and Seabra, 2005; Star et al., 2005). After delivery to their respective membranes, Rabs are activated by replacement of GDP by GTP. GTP-bound Rabs are thought to orchestrate the assembly of cargo contents, motor association, and docking interactions between donor and target membranes, whereas Rab3-GDP is presumably generated during or after exocytosis, allowing Rab3 release from the target membrane (Fischer von Mollard et al., 1991; Stahl et al., 1994; Sakisaka et al., 2002; Star et al., 2005). Recent data, however, showed that Rab3A knockdown, knock-out, or overexpression of GTP-locked mutant Rab3A significantly decreases the number of vesicles docked at the plasma membrane without altering the kinetics of individual exocytotic events (Schluter et al., 2006; Tsuboi and Fukuda, 2006; Coleman et al., 2007; Handley et al., 2007; van Weering et al., 2007). Together with these studies, our data argue that Rab3A does not play an essential role in vesicle fusion but rather in the transport of vesicles to the plasma membrane. In addition, our studies suggest that Rab3A-GTP hydrolysis might take place before the vesicle docks to the target membrane.

The well established role of Rabs in protein sorting led us to examine alterations in the composition of APP-containing mem- 
brane cargoes induced by reduced Rab3A activity. Significantly, we found reduced levels of kinesin-1C and other protein cargoes in APP-containing membranous organelles obtained from p $130^{-1-}$ mouse brain, in which Rab3A GTPase activity is inhibited. Together, our findings suggest a model in which Rab3 GTPase activity is required for correct assembly of APP and other membrane proteins (i.e., syntaxin-1, SNAP25, and synapsin-I) in a biochemically distinct transport vesicle type. In addition, our results suggest that Rab3A may regulate the association of kinesin-1C to the APP transport vesicle (Fig. 8).

\section{APP can be cleaved by $\alpha$-secretase in transport vesicles}

The subcellular compartment and spatial regulation of APP processing secretases, such as ADAM10, ADAM17, BACE1, or PS1, remains to be determined, because this information is critical for understanding the biology of APP. Early suggestions that BACE1 and PS1 are cotransported with APP in anterogradely transported axonal vesicles (Kamal et al., 2001) were not confirmed in subsequent studies (Lazarov et al., 2005; Goldsbury et al., 2006). Our studies here found that APP/kinesin-1-immunoisolated membrane fractions did not contain detectable levels of ADAM17, BACE1, PS1, or Nicastrin. Of the secretase components examined, only ADAM10 was detected in these membrane preparations. Remarkably, sAPP was detected in the isolated membrane fractions after in vitro incubations. Generation of this sAPP was blocked by a zinc chelator/inhibitor of $\alpha$-secretase, consistent with the possibility that $\alpha$-secretase activity is present in the immunoisolated organelle fractions. However, compared with full-length APP, the amount of sAPP was $<1 \%$, indicating that only low amounts of sAPP might be generated on its way to the plasma membrane. Alternatively, the process of immunoisolation may lead to activation of associated ADAM10. The physiological significance of this processing in immunoisolated vesicles remains to be determined, but therapeutic strategies affecting APP packaging in transport vesicles might help reduce $A \beta$ generation.

Together, our data suggest a novel, Rab3A-dependent mechanism for the coordinated regulation of APP sorting and axonal transport events, giving important insights into the physiological and pathogenic function of APP.

\section{References}

Ali BR, Seabra MC (2005) Targeting of Rab GTPases to cellular membranes. Biochem Soc Trans 33:652-656.

Amaratunga A, Morin PJ, Kosik KS, Fine RE (1993) Inhibition of kinesin synthesis and rapid anterograde axonal transport in vivo by an antisense oligonucleotide. J Biol Chem 268:17427-17430.

Back S, Haas P, Tschäpe JA, Gruebl T, Kirsch J, Müller U, Beyreuther K, Kins S (2007) beta-amyloid precursor protein can be transported independent of any sorting signal to the axonal and dendritic compartment. J Neurosci Res 85:2580-2590.

Bloom GS, Richards BW, Leopold PL, Ritchey DM, Brady ST (1993) GTP gamma $\mathrm{S}$ inhibits organelle transport along axonal microtubules. J Cell Biol 120:467-476.

Burstein ES, Brondyk WH, Macara IG, Kaibuchi K, Takai Y (1993) Regulation of the GTPase cycle of the neuronally expressed Ras-like GTPbinding protein Rab3A. J Biol Chem 268:22247-22250.

Coleman WL, Bill CA, Bykhovskaia M (2007) Rab3a deletion reduces vesicle docking and transmitter release at the mouse diaphragm synapse. Neuroscience 148:1-6.

DeBoer SR, You Y, Szodorai A, Kaminska A, Pigino G, Nwabuisi E, Wang B, Estrada-Hernandez T, Kins S, Brady ST, Morfini G (2008) Conventional kinesin holoenzymes are composed of heavy and light chain homodimers. Biochemistry 47:4535-4543.

de Wit H, Lichtenstein Y, Geuze HJ, Kelly RB, van der Sluijs P, Klumperman J (1999) Synaptic vesicles form by budding from tubular extensions of sorting endosomes in PC12 cells. Mol Biol Cell 10:4163-4176.
Deneka M, Neeft M, van der Sluijs P (2003) Regulation of membrane transport by rab GTPases. Crit Rev Biochem Mol Biol 38:121-142.

Dresbach T, Qualmann B, Kessels MM, Garner CC, Gundelfinger ED (2001) The presynaptic cytomatrix of brain synapses. Cell Mol Life Sci 58:94-116.

Ferreira A, Niclas J, Vale RD, Banker G, Kosik KS (1992) Suppression of kinesin expression in cultured hippocampal neurons using antisense oligonucleotides. J Cell Biol 117:595-606.

Ferreira A, Caceres A, Kosik KS (1993) Intraneuronal compartments of the amyloid precursor protein. J Neurosci 13:3112-3123.

Fischer von Mollard G, Mignery GA, Baumert M, Perin MS, Hanson TJ, Burger PM, Jahn R, Südhof TC (1990) rab3 is a small GTP-binding protein exclusively localized to synaptic vesicles. Proc Natl Acad Sci U S A 87:1988-1992.

Fischer von Mollard G, Südhof TC, Jahn R (1991) A small GTP-binding protein dissociates from synaptic vesicles during exocytosis. Nature 349:79-81.

Fonte J, Miklossy J, Atwood C, Martins R (2001) The severity of cortical Alzheimer's type changes is positively correlated with increased amyloidbeta levels: resolubilization of amyloid-beta with transition metal ion chelators. J Alzheimers Dis 3:209-219.

Fukui K, Sasaki T, Imazumi K, Matsuura Y, Nakanishi H, Takai Y (1997) Isolation and characterization of a GTPase activating protein specific for the Rab3 subfamily of small G proteins. J Biol Chem 272:4655-4658.

Goldsbury C, Mocanu MM, Thies E, Kaether C, Haass C, Keller P, Biernat J, Mandelkow E, Mandelkow EM (2006) Inhibition of APP trafficking by tau protein does not increase the generation of amyloid-beta peptides. Traffic 7:873-888.

Handley MT, Haynes LP, Burgoyne RD (2007) Differential dynamics of Rab3A and Rab27A on secretory granules. J Cell Sci 120:973-984.

Hilbich C, Mönning U, Grund C, Masters CL, Beyreuther K (1993) Amyloid-like properties of peptides flanking the epitope of amyloid precursor protein-specific monoclonal antibody 22C11. J Biol Chem 268:26571-26577.

Inomata H, Nakamura Y, Hayakawa A, Takata H, Suzuki T, Miyazawa K, Kitamura N (2003) A scaffold protein JIP-1b enhances amyloid precursor protein phosphorylation by JNK and its association with kinesin light chain 1. J Biol Chem 278:22946-22955.

Johannes L, Lledo PM, Roa M, Vincent JD, Henry JP, Darchen F (1994) The GTPase Rab3a negatively controls calcium-dependent exocytosis in neuroendocrine cells. EMBO J 13:2029-2037.

Kaether C, Skehel P, Dotti CG (2000) Axonal membrane proteins are transported in distinct carriers: a two-color video microscopy study in cultured hippocampal neurons. Mol Biol Cell 11:1213-1224.

Kamal A, Stokin GB, Yang Z, Xia CH, Goldstein LS (2000) Axonal transport of amyloid precursor protein is mediated by direct binding to the kinesin light chain subunit of kinesin-I. Neuron 28:449-459.

Kamal A, Almenar-Queralt A, LeBlanc JF, Roberts EA, Goldstein LS (2001) Kinesin-mediated axonal transport of a membrane compartment containing beta-secretase and presenilin-1 requires APP. Nature 414:643-648.

Kins S, Lauther N, Szodorai A, Beyreuther K (2006) Subcellular trafficking of the amyloid precursor protein gene family and its pathogenic role in Alzheimer's disease. Neurodegener Dis 3:218-226.

Koo EH, Sisodia SS, Archer DR, Martin LJ, Weidemann A, Beyreuther K, Fischer P, Masters CL, Price DL (1990) Precursor of amyloid protein in Alzheimer disease undergoes fast anterograde axonal transport. Proc Natl Acad Sci U S A 87:1561-1565.

Kratohvil JP (1984) Size of bile salt micelles: techniques, problems and results. Hepatology 4:85S-97S.

Kuan YH, Gruebl T, Soba P, Eggert S, Nesic I, Back S, Kirsch J, Beyreuther K, Kins S (2006) PATla modulates intracellular transport and processing of APP, APLP1 and APLP2. J Biol Chem 281:40114-40123.

Lawrence CJ, Dawe RK, Christie KR, Cleveland DW, Dawson SC, Endow SA, Goldstein LS, Goodson HV, Hirokawa N, Howard J, Malmberg RL, McIntosh JR, Miki H, Mitchison TJ, Okada Y, Reddy AS, Saxton WM, Schliwa M, Scholey JM, Vale RD, Walczak CE, Wordeman L (2004) A standardized kinesin nomenclature. J Cell Biol 167:19-22.

Lazarov O, Morfini GA, Lee EB, Farah MH, Szodorai A, DeBoer SR, Koliatsos VE, Kins S, Lee VM, Wong PC, Price DL, Brady ST, Sisodia SS (2005) Axonal transport, amyloid precursor protein, kinesin-1, and the processing apparatus: revisited. J Neurosci 25:2386-2395.

Lazarov O, Morfini GA, Pigino G, Gadadhar A, Chen X, Robinson J, Ho H, 
Brady ST, Sisodia SS (2007) Impairments in fast axonal transport and motor neuron deficits in transgenic mice expressing familial Alzheimer's disease-linked mutant presenilin 1. J Neurosci 27:7011-7020.

Li JY, Jahn R, Hou XE, Kling-Petersen A, Dahlström A (1996a) Distribution of Rab3a in rat nervous system: comparison with other synaptic vesicle proteins and neuropeptides. Brain Res 706:103-112.

Li ZW, Stark G, Götz J, Rülicke T, Gschwind M, Huber G, Müller U, Weissmann C (1996b) Generation of mice with a 200-kb amyloid precursor protein gene deletion by Cre recombinase-mediated site-specific recombination in embryonic stem cells. Proc Natl Acad Sci U S A 93:6158-6162.

Morfini G, Quiroga S, Rosa A, Kosik K, Cáceres A (1997) Suppression of KIF2 in PC12 cells alters the distribution of a growth cone nonsynaptic membrane receptor and inhibits neurite extension. J Cell Biol 138:657-669.

Nagano F, Sasaki T, Fukui K, Asakura T, Imazumi K, Takai Y (1998) Molecular cloning and characterization of the noncatalytic subunit of the Rab3 subfamily-specific GTPase-activating protein. J Biol Chem 273:24781-24785.

Okada Y, Yamazaki H, Sekine-Aizawa Y, Hirokawa N (1995) The neuronspecific kinesin superfamily protein KIF1A is a unique monomeric motor for anterograde axonal transport of synaptic vesicle precursors. Cell 81:769-780.

Partearroyo MA, Goñi FM, Katime I, Alonso A (1988) Micellar properties of the zwitterionic bile derivative CHAPS. Biochem Int 16:259-265.

Pfister KK, Wagner MC, Stenoien DL, Brady ST, Bloom GS (1989) Monoclonal antibodies to kinesin heavy and light chains stain vesicle-like structures, but not microtubules, in cultured cells. J Cell Biol 108:1453-1463.

Reinhard C, Hébert SS, De Strooper B (2005) The amyloid-beta precursor protein: integrating structure with biological function. EMBO J 24:3996-4006.

Rusu P, Jansen A, Soba P, Kirsch J, Löwer A, Merdes G, Kuan YH, Jung A, Beyreuther K, Kjaerulff O, Kins S (2007) Axonal accumulation of synaptic markers in APP transgenic Drosophila depends on the NPTY motif and is paralleled by defects in synaptic plasticity. Eur J Neurosci 25:1079-1086.

Sabo SL, Ikin AF, Buxbaum JD, Greengard P (2003) The amyloid precursor protein and its regulatory protein, FE65, in growth cones and synapses in vitro and in vivo. J Neurosci 23:5407-5415.

Sakane A, Manabe S, Ishizaki H, Tanaka-Okamoto M, Kiyokage E, Toida K, Yoshida T, Miyoshi J, Kamiya H, Takai Y, Sasaki T (2006) Rab3 GTPaseactivating protein regulates synaptic transmission and plasticity through the inactivation of Rab3. Proc Natl Acad Sci U S A 103:10029-10034.

Sakisaka T, Meerlo T, Matteson J, Plutner H, Balch WE (2002) RabalphaGDI activity is regulated by a Hsp90 chaperone complex. EMBO J 21:6125-6135.

Satpute-Krishnan P, DeGiorgis JA, Conley MP, Jang M, Bearer EL (2006) A peptide zipcode sufficient for anterograde transport within amyloid precursor protein. Proc Natl Acad Sci U S A 103:16532-16537.

Schlüter OM, Schmitz F, Jahn R, Rosenmund C, Südhof TC (2004) A complete genetic analysis of neuronal Rab3 function. J Neurosci 24:6629-6637.

Schlüter OM, Basu J, Südhof TC, Rosenmund C (2006) Rab3 superprimes synaptic vesicles for release: implications for short-term synaptic plasticity. J Neurosci 26:1239-1246.

Selkoe DJ (2001) Alzheimer's disease: genes, proteins, and therapy. Physiol Rev 81:741-766.
Shapira M, Zhai RG, Dresbach T, Bresler T, Torres VI, Gundelfinger ED, Ziv NE, Garner CC (2003) Unitary assembly of presynaptic active zones from Piccolo-Bassoon transport vesicles. Neuron 38:237-252.

Simons M, Ikonen E, Tienari PJ, Cid-Arregui A, Mönning U, Beyreuther K, Dotti CG (1995) Intracellular routing of human amyloid protein precursor: axonal delivery followed by transport to the dendrites. J Neurosci Res 41:121-128.

Soba P, Eggert S, Wagner K, Zentgraf H, Siehl K, Kreger S, Löwer A, Langer A, Merdes G, Paro R, Masters CL, Müller U, Kins S, Beyreuther K (2005) Homo- and heterodimerization of APP family members promotes intercellular adhesion. EMBO J 24:3624-3634.

Stahl B, von Mollard GF, Walch-Solimena C, Jahn R (1994) GTP cleavage by the small GTP-binding protein Rab3A is associated with exocytosis of synaptic vesicles induced by alpha-latrotoxin. J Biol Chem 269:24770-24776.

Stamer K, Vogel R, Thies E, Mandelkow E, Mandelkow EM (2002) Tau blocks traffic of organelles, neurofilaments, and APP vesicles in neurons and enhances oxidative stress. J Cell Biol 156:1051-1063.

Star EN, Newton AJ, Murthy VN (2005) Real-time imaging of Rab3a and Rab5a reveals differential roles in presynaptic function. J Physiol 569:103-117.

Takamori S, Holt M, Stenius K, Lemke EA, Grønborg M, Riedel D, Urlaub H, Schenck S, Brügger B, Ringler P, Müller SA, Rammner B, Gräter F, Hub JS, De Groot BL, Mieskes G, Moriyama Y, Klingauf J, Grubmüller H, Heuser J, Wieland F, Jahn R (2006) Molecular anatomy of a trafficking organelle. Cell 127:831-846.

Tienari PJ, De Strooper B, Ikonen E, Simons M, Weidemann A, Czech C, Hartmann T, Ida N, Multhaup G, Masters CL, Van Leuven F, Beyreuther K, Dotti CG (1996) The beta-amyloid domain is essential for axonal sorting of amyloid precursor protein. EMBO J 15:5218-5229.

Torroja L, Packard M, Gorczyca M, White K, Budnik V (1999) The Drosophila beta-amyloid precursor protein homolog promotes synapse differentiation at the neuromuscular junction. J Neurosci 19:7793-7803.

Tsuboi T, Fukuda M (2006) Rab3A and Rab27A cooperatively regulate the docking step of dense-core vesicle exocytosis in PC12 cells. J Cell Sci 119:2196-2203.

van Weering JR, Toonen RF, Verhage M (2007) The role of Rab3a in secretory vesicle docking requires association/dissociation of guanidine phosphates and Munc18-1. PLoS ONE 2:e616.

Wang P, Yang G, Mosier DR, Chang P, Zaidi T, Gong YD, Zhao NM, Dominguez B, Lee KF, Gan WB, Zheng H (2005) Defective neuromuscular synapses in mice lacking amyloid precursor protein (APP) and APPLike protein 2. J Neurosci 25:1219-1225.

Weidemann A, König G, Bunke D, Fischer P, Salbaum JM, Masters CL, Beyreuther K (1989) Identification, biogenesis, and localization of precursors of Alzheimer's disease A4 amyloid protein. Cell 57:115-126.

Yang L, Wang B, Long C, Wu G, Zheng H (2007) Increased asynchronous release and aberrant calcium channel activation in amyloid precursor protein deficient neuromuscular synapses. Neuroscience 149:768-778.

Zhai RG, Vardinon-Friedman H, Cases-Langhoff C, Becker B, Gundelfinger ED, Ziv NE, Garner CC (2001) Assembling the presynaptic active zone: a characterization of an active one precursor vesicle. Neuron 29:131-143. 